\title{
Understanding the organic micropollutants transport mechanisms in the fertilizer-drawn forward osmosis process
}

\author{
Youngjin Kim ${ }^{\text {a }}$, Sheng Li ${ }^{\text {a,b }}$, Sherub Phuntsho ${ }^{c}$, Ming Xie ${ }^{\text {d }}$, Ho Kyong Shon ${ }^{\text {c* }}$, Noreddine \\ Ghaffour ${ }^{\text {a* }}$ \\ ${ }^{a}$ King Abdullah University of Science and Technology (KAUST), Water Desalination and Reuse Center (WDRC), \\ Division of Biological \& Environmental Science \& Engineering (BESE), Thuwal 23955-6900, Saudi Arabia \\ ${ }^{b}$ Guangzhou Institute of Advanced Technology, Chinese Academy of Science, Haibin Road \#1121, Nansha district, \\ Guangzhou, China \\ ${ }^{c}$ Centre for Technology in Water and Wastewater, School of Civil and Environmental Engineering, University of \\ Technology Sydney (UTS), Post Box 129, Broadway, NSW 2007, Australia \\ ${ }^{d}$ Department of Chemical Engineering, University of Bath, Claverton Down, Bath BA2 7AY, UK \\ *Co-corresponding authors: Ho Kyong Shon, Tel.: +61-2-9514-2629; E-mail: Hokyong.Shon-1@uts.edu.au, \\ Noreddine Ghaffour.Tel.+966-128082180,E-mail: noreddine.ghaffour@kaust.edu.sa
}

\section{Abstract}

We systematically investigated the transport mechanisms of organic micropollutants (OMPs) in a fertilizer-drawn forward osmosis (FDFO) membrane process. Four representative OMPs, i.e., atenolol, atrazine, primidone, and caffeine, were chosen for their different molecular weights and structural characteristics. All the FDFO experiments were conducted with the membrane active layer on the feed solution (FS) side using three different fertilizer draw solutions (DS): potassium chloride $(\mathrm{KCl})$, monoammonium phosphate (MAP), and diammonium phosphate (DAP) due to their different properties (i.e., osmotic pressure, diffusivity, viscosity and solution $\mathrm{pH}$ ). Using $\mathrm{KCl}$ as the DS resulted in both the highest water flux and the highest reverse solute flux (RSF), while MAP and DAP resulted in similar water fluxes with varying RSF. The $\mathrm{pH}$ of the FS increased with DAP as the DS due to the reverse diffusion of $\mathrm{NH}_{4}{ }^{+}$ions from the DS toward the FS, while for MAP and DAP DS, the $\mathrm{pH}$ of the FS was not impacted. The OMPs transport behavior (OMPs flux) was evaluated and compared with a simulated OMPs flux obtained via the pore-hindrance transport model to identify the effects of the OMPs structural properties. When MAP was used as DS, the OMPs flux was dominantly influenced by the physicochemical properties (i.e., hydrophobicity and surface charge). Those OMPs with positive charge and more hydrophobic, exhibited higher forward OMP fluxes. With DAP as the DS, the more hydrated FO membrane (caused by increased 
$33 \mathrm{pH}$ ) as well as the enhanced RSF hindered OMPs transport through the FO membrane. With KCl

34 as DS, the structural properties of the OMPs were dominant factors in the OMPs flux, however the

35 higher $\mathrm{RSF}$ of the $\mathrm{KCl}$ draw solute may likely hamper the OMPs transport through the membrane

36 especially those with higher MW (e.g., atenolol). The pore-hindrance model can be instrumental

37 in understanding the effects of the hydrodynamic properties and the surface properties on the

38 OMPs transport behaviors.

40 Keywords: FDFO; Organic micropollutants; Fertilizer properties; OMPs properties; Pore-

41 hindrance model.

\section{1. Introduction}

44 Organic micropollutants (OMPs), such as pharmaceutical and personal care products, pesticides,

45 herbicides, household chemicals, have become a growing risk to public health and the environment

46 in the past decades (Arslan et al., 2017; Snyder et al., 2003; Tang et al., 2013). Despite the

47 significant possible impact of OMPs, no legal discharge limits have been set by most countries.

48 Only a few countries monitor and manage OMPs discharge through a watch list (Barbosa et al.,

49 2016). While wastewater reuse can sustain freshwater resources and provide necessary nutrients

50 for plants (Jeong et al., 2016), the presence of OMPs in raw sewage (Escher et al., 2014) directly

51 influences and reduces its reuse, particularly in the agricultural sector. A more efficient process

52 for the removal of OMPs from wastewater could facilitate the reuse and discharge of wastewater.

53 The OMPs removal efficiencies of conventional biological wastewater treatment technologies,

54 such as the activated sludge process, are reported to range from $0 \%$ to $90 \%$ depending on OMPs

55 properties, sludge properties, and operating conditions (Grandclément et al., 2017). Such variation

56 limits the consistent and safe reuse of wastewater (Bernhard et al., 2006; Carballa et al., 2004;

57 Clara et al., 2005; Grandclément et al., 2017; Pérez et al., 2005). To enhance the efficiency of

58 biological treatments, a membrane bioreactor (MBR), which combined a bioreactor with

59 microfiltration (MF) or ultrafiltration (UF), was proposed (Krzeminski et al., 2017). This MBR

60 advertised a small environmental footprint, high effluent quality, and complete rejection of

61 suspended solids, and could be effective in the treatment of OMPs that were not readily removed

62 by the activated sludge treatment process (Bernhard et al., 2006; Clara et al., 2005; Hai et al., 2011). 
63 However, this MBR technology did not meet the permissible limits, e.g., $1 \mu \mathrm{g} \mathrm{L}^{-1}$ for irrigation 64 reuse ((NSW), 2004), for adequate water-reuse quality.

65 Wastewater reclamation and reuse is considered more cost-effective and environmentally friendly than seawater desalination for solving water-scarcity issues because it has low energy 67 requirements and additional water does not need to be transferred to inland regions (Shannon et al., 2008). Advanced membrane processes, such as nanofiltration (NF) or reverse osmosis (RO), have been widely employed in wastewater reuse to improve the efficiency of OMPs removal, since even very low concentrations of many OMPs may have a harmful impact on the environment (Fujioka et al., 2015; Radjenović et al., 2008; Snyder et al., 2003). Ionic or charged OMPs are rejected more easily by RO membranes with a negative surface charge, while hydrophobic nonionic OMPs are rejected at decreasing rates with operation (Xu et al., 2005). Also, the rejection of negatively charged OMPs was observed to be higher than that of positively charged OMPs, despite similar molecular weights (Fujioka et al., 2015). While both the NF and RO membranes achieved high rejections of OMPs, they also failed to retain some OMPs, implying that the reuse of wastewater treated with these membranes may pose a risk (Radjenović et al., 2008). Furthermore, pressure-driven membrane-based desalting processes have many disadvantages, e.g., high energy demands and severe membrane fouling caused by high hydraulic pressure (Chong et al., 2015; Ghaffour et al., 2013; Xie et al., 2015).

To overcome these problems, forward osmosis (FO) was recently presented as a potential alternative to the conventional, pressure-driven membrane processes used for desalination (Lee et al., 2010). FO uses a high concentration gradient as its driving force, which not only generates a high water flux, but also reversely diffuses the draw solutes towards the feed solution (FS). As the reverse solute flux (RSF) moves in the opposite direction of the OMPs solute flux, it hinders the

86 OMPs flux. Thus, the FO process was reported to have a higher OMPs removal efficiency than the RO process (Kim et al., 2012; Xie et al., 2012a).

Operational conditions (i.e., water flux, solution $\mathrm{pH}$, membrane orientation, and working temperature) also significantly affect OMPs rejections (Jamil et al., 2016; Jin et al., 2012; Xie et al., 2013). The OMPs removal of the FO process was much less efficient when the active layer of

91 the membrane was facing the draw solution (DS), i.e., AL-DS, than when the active layer was 92 oriented towards the feed solution (FS), i.e., AL-FS (Jin et al., 2012; Xie et al., 2012b). In the AL- 
93 FS orientation, an internal concentration polarization (ICP) occurred, which not only increased the

94 OMPs concentration inside the membrane support layer, but also severely restricted the backward 95 diffusion (mass transfer) of the OMPs into the bulk FS. Thus, the OMPs flux was enhanced and 96 the efficiency of its removal was reduced (Alturki et al., 2013; Jin et al., 2012). At high FS 97 temperatures, the OMPs rejection decreased due to the enhanced OMPs diffusivity; the opposite 98 effect was observed at high DS temperatures. The OMPs rejection increased at high DS 99 temperatures because the enhanced water flux had a diluting effect and the slightly elevated reverse 100 solute flux had a hindrance effect (Xie et al., 2013). The solution pH also significantly influenced 101 the ionic OMPs rejection (Xie et al., 2012b). The thin-film composite (TFC) FO membrane based 102 on polyamide (PA) was reported to have a much better OMPs rejection due to pore hydration than 103 FO membranes based on cellulose triacetate (CTA), even though TFC membranes have larger pore 104 sizes (Xie et al., 2014b). Membrane fouling also significantly influenced OMPs rejection, and a 105 previous study observed that the initial FO water flux played a key role in both membrane fouling 106 and OMPs rejection (Jin et al., 2012; Xie et al., 2014a). Interfacial interactions between foulants 107 and membrane are decisive forces to membrane fouling ( $\mathrm{Qu}$ et al., 2018; Teng et al., 2019), 108 potentially affecting the OMPs rejection. The surface characteristics of the fouling layer in a fouled 109 FO membrane could also influence OMPs rejection (Valladares Linares et al., 2011). The 110 characteristics of the fouling/cake layer may be an important factor affecting the OMPs rejection 111 due to their different resistance depending on their composition (Teng et al., 2018; Zhang et al., 112 2018). However, since the FO process simply converts a concentrated DS into a diluted DS, 113 additional desalting processes are needed to produce pure water while the diluted DS is 114 reconcentrated and regenerated for a sustainable operation (Chekli et al., 2016).

115 The fertilizer-drawn forward osmosis (FDFO) process has received significant attention 116 because a diluted fertilizer DS can be directly applied in irrigation with no need for DS separation 117 (Kim et al., 2018; Kim et al., 2017d). FDFO was employed in irrigation reuse by integrating it 118 with an anaerobic MBR (AnMBR) (Kim et al., 2016), and was successful in concentrating 119 municipal wastewater (Chekli et al., 2017b). However, one of the major concerns with FDFO is 120 the high reverse diffusion of inorganic fertilizers towards the bioreactor, as it negatively impacts 121 the anaerobic microorganisms, reducing biogas production (Kim et al., 2017a; Li et al., 2017b). 122 Also, biofouling on the osmotic membrane surface is considerably influenced by the properties of 
123 the fertilizers used as the DS (Li et al., 2017a). Despite these drawbacks, FDFO was found to be

124 feasible for wastewater treatment, and it has exhibited high OMPs removal during the treatment

125 of AnMBR effluent (Kim et al., 2017c). When commercial hydroponic fertilizer solutions were

126 evaluated for use as the DS, the fertilizer solution diluted by a pilot-scale FDFO system was found

127 to be appropriate for a hydroponic application (Chekli et al., 2017a). Though many studies have

128 attempted to understand the FDFO process for wastewater treatment, the OMPs transport

129 mechanisms in the FDFO process have not yet been well elucidated.

130 Therefore, the aim of this study is to investigate the transport mechanisms of the OMPs in the 131 FDFO process. Four different OMPs (atenolol, atrazine, primidone, and caffeine) were used to

132 investigate the effects of molecular weight and physicochemical properties such as hydrophobicity

133 and surface charge. Caffeine and primidone were compared due to their different molecular

134 weights and similar surface physicochemical properties (i.e., neutral surface charges and similar

135 hydrophobicity). Atrazine and primidone were examined since they have different

136 hydrophobicities, but similar molecular weights and neutral surface charges. Finally, atenolol was

137 examined to determine the effect of a positive surface charge on the OMPs transport behaviors.

138 For evaluation, three different fertilizers, namely potassium chloride $(\mathrm{KCl})$, monoammonium

139 phosphate, i.e., $\mathrm{NH}_{4} \mathrm{H}_{2} \mathrm{PO}_{4}$ (MAP), and diammonium phosphate, i.e., $\left(\mathrm{NH}_{4}\right)_{2} \mathrm{HPO}_{4}(\mathrm{DAP})$ ) were

140 employed as draw solutes in this study because they have different properties and performances

141 (i.e., water flux, RSF, and pH change of the FS) as reported in the FDFO process (Kim et al.,

142 2017c). To identify the effect of the physicochemical properties of the OMPs surfaces on their

143 transport, the pore-hindrance transport model, which has been utilized to estimate rejections by

144 size exclusion (Rodgers and Miller, 1993), was employed and compared to the experimental data.

146 2. Materials and methods

147 2.1. Representative organic micropollutants (OMPs)

148 Four different OMPs, i.e., atenolol, atrazine, caffeine, and primidone, were provided by Sigma 149 Aldrich in a powder form. Their key physicochemical characteristics are presented in Table 1. The 150 diffusivity of the solute was calculated based on the Wilke and Chang equation, while the Stokes151 Einstein equation was used to calculate the Stokes radius (Wilke and Chang, 1955). To prepare a 
$1524 \mathrm{~g} \mathrm{~L}^{-1}$ stock solution, $4 \mathrm{mg}$ OMPs were added to $1 \mathrm{~mL}$ methanol; the stock solution was stored 153 until use at about $4{ }^{\circ} \mathrm{C}$.

155 Table 1: Key physicochemical characteristics of the OMPs used in this study.

\begin{tabular}{l||l|l|l|l}
\hline & Caffeine & Atrazine & Primidone & Atenolol \\
\hline \hline Application & Stimulant & Herbicide & Anticonvulsant & Beta-blocker \\
\hline Formula & $\mathrm{C}_{8} \mathrm{H}_{10} \mathrm{~N}_{4} \mathrm{O}_{2}$ & $\mathrm{C}_{8} \mathrm{H}_{14} \mathrm{ClN}_{5}$ & $\mathrm{C}_{12} \mathrm{H}_{14} \mathrm{~N}_{2} \mathrm{O}_{2}$ & $\mathrm{C}_{14} \mathrm{H}_{22} \mathrm{~N}_{2} \mathrm{O}_{3}$ \\
\hline \begin{tabular}{|l|l|l} 
Molecular weight \\
$(\mathrm{g} / \mathrm{mol})$
\end{tabular} & 194 & 216 & 218 & 266 \\
\hline $\begin{array}{l}\text { Charge } \\
(\text { at } \mathrm{pH} 6.5)\end{array}$ & Neutral & Neutral & Neutral & Positive \\
\hline $\begin{array}{l}\text { Log } D^{\mathrm{a}, \mathrm{b}} \\
(\text { at } \mathrm{pH} 6.5)\end{array}$ & -0.63 & 2.64 & 0.83 & -2.09 \\
\hline$p \mathrm{~K}_{\mathrm{a}}^{\mathrm{a}}$ & 0.52 & 2.27 & 12.26 & 9.6 \\
\hline $\begin{array}{l}\text { Diffusivity } \\
\left.\mathrm{m}^{2} / \mathrm{s}\right)\end{array}$ & 6.46 & 6.10 & 6.07 & 5.46 \\
\hline $\begin{array}{l}\text { Stokes radius } \\
(\mathrm{nm})\end{array}$ & 0.33 & 0.35 & 0.35 & 0.39 \\
\hline
\end{tabular}

${ }^{\mathrm{a}}$ Information about the surface charge, Log D, and pKa was adopted from the ChemSpider website (http://www.chemspider.com).

${ }^{\mathrm{b}}$ High $\log D$ values indicate high hydrophobicity.

${ }^{\mathrm{c}}$ Diffusivity at $20^{\circ} \mathrm{C}$ was calculated based on the Wilke and Chang equation (Wilke and Chang, 1955).

${ }^{\mathrm{d}}$ Stokes radius was calculated based on the Stokes-Einstein equation (Wilke and Chang, 1955).

\subsection{FO membrane and draw solutions (DS)}

158 CTA FO membranes from HTI (Hydration Technology Innovations, USA) were used in the present study. The membrane transport parameters were adopted from our previous study (Kim et al., 2016), and are presented in Table S1, Supplementary Data. The average pore radius and structural factors of FO membranes (Table S2, Supplementary Data) from another study (Xie et al., 2014b) were employed and utilized to solve the pore-hindrance transport model. The surface

163 characteristics of the FO membrane, such as contact angle, zeta potential, and roughness of the

164 selective layer, are presented in Table 2. A Sigma 701 microbalance (KSV Instrument Ltd.,

165 Finland) was used to determine the surface contact angle. The zeta potential of the membrane 166 surface was measured using a streaming current electrokinetic analyzer (SurPass, Anton Paar

$167 \mathrm{GmbH}$, Austria). The roughness of the membrane surface was characterized using atomic force 168 microscopy (AFM) (Dimension Icon, Germany). At least three measurements were taken for 169 each membrane sample and the average value was used. 
171 Table 2. Surface characteristics of an HTI CTA FO membrane. The zeta potential was measured 172 at $\mathrm{pH} 6.5$ with $0.01 \mathrm{M} \mathrm{KCl}$ as the background electrolyte solution. The contact angle and the 173 roughness were determined at $\mathrm{pH} 6.5$ and room temperature. (Average \pm standard deviation)

\begin{tabular}{l|l|l|l}
\hline & Contact angle & Zeta potential & Roughness \\
\hline \hline CTA FO membrane & $79.5 \pm 5.2^{\circ}$ & $-6.87 \pm 2.07 \mathrm{mV}$ & $13.33 \pm 2.89 \mathrm{~nm}$ \\
\hline
\end{tabular}

175 Three reagent-grade fertilizers ( $\mathrm{KCl}$, MAP and DAP) were used as received from Sigma 176 Aldrich for the DS. The DS was prepared by dissolving an appropriate amount of fertilizer salt in 177 deionized (DI) water. The thermodynamic properties of the fertilizer chemicals are presented in 178 Table S3, Supplementary Data.

\subsection{FDFO experimental studies}

181 For all the experimental studies, a lab-scale FO unit consisting of two variable-speed gear pumps 182 (Cole-Parmer, USA), a standard membrane cell, two flow meters, and a balance was used. The FO 183 membrane cell contained two symmetric flow channels $(100 \mathrm{~mm}$ length $\times 20 \mathrm{~mm}$ width $\times 3 \mathrm{~mm}$ 184 depth) for the FS and DS, and the FO membrane was installed between these two channels. The 185 FO membrane cell was operated at a crossflow rate of $8.5 \mathrm{~cm} \mathrm{~s}^{-1}$ in the direction of the co-current 186 crossflow. The FO process was operated in batch mode, meaning that both the FS and DS were 187 recirculated back to their respective solution tanks, which were maintained at a constant 188 temperature of $20 \pm 1{ }^{\circ} \mathrm{C}$ using a temperature control system. The experiments were carried out 189 for a duration of 10 hours, using a fertilizer DS (either $1 \mathrm{M}$ or $2 \mathrm{M}$ ) with the AL-FS membrane 190 orientation. The OMPs transport mechanism was investigated by adding $10 \mu \mathrm{L}$ OMPs stock 191 solution ( $1 \mathrm{~g} \mathrm{~L}^{-1}$ each OMPs) into $1 \mathrm{~L} \mathrm{FS}$ to achieve a $10 \mu \mathrm{g} \mathrm{L}^{-1}$ concentration of each OMP. The 192 change in the diluted DS volume was recorded by placing the DS tank on a digital weighing scale 193 (Mettler Toledo, USA) connected to a PC for data logging; these data were used to calculate the 194 water flux using Eq. (1),

$$
J_{w}=\frac{\Delta V_{D S}}{A_{m} t}
$$

196 where $J_{w}$ refers to the measured water flux $\left(\mathrm{L} \mathrm{m}^{-2} \mathrm{~h}^{-1}\right), \Delta V_{D S}$ is the change in DS volume (L) during 197 operation, $A_{m}$ refers to the membrane area $\left(\mathrm{m}^{2}\right)$, and $t$ refers to the operation time (h). After the 198 experiments, the concentrated FS was sampled and analyzed to obtain RSF using Eq. (2), 
where $J_{s}$ refers to RSF (mol m $\mathrm{m}^{-2} \mathrm{~h}^{-1}$ ) and $\Delta m_{D S}$ is the change in the mass of the draw solutes in the FS during operation (mol). The detailed experimental procedures are described in our previous studies (Kim et al., 2017c; Kim et al., 2017d).

\subsection{Analytical methods for OMPs}

205 The OMPs concentrations were obtained based on methods used in our earlier study (Kim et al., 2017c). After the experiments, $100 \mathrm{~mL}$ samples were collected, to which $10 \mu \mathrm{L}$ isotopes were added (Cambridge Isotope Laboratories, Inc., USA). The OMPs were removed from the samples using solid-phase extraction (Dione Autotrace 280 and Oasis cartridges). Then, the evaporation for extrated samples was conducted at temperature of $60^{\circ} \mathrm{C}$ for 1 hour and LC/MS grade methaol was added in evaporated samples to make $1 \mathrm{~mL}$ samples. Finally, the OMPs concentrations were measured using liquid chromatography (Agilent Technology 1260 Infinity LC unit, USA) and mass spectrometry (AB SCIEX QTRAP 5500 mass spectrometer, Applied Biosystems, USA). The

213 recovery ratio (i.e., the ratio of the peak areas before and after extraction) was considered to

214 evaluate the loss of OMPs during the extraction and evaporation processes and to calculate the 215 final concentration of OMPs by multiplying the measured concentrations by the obtained recovery 216 ratio. Then, the OMPs forward flux (toward DS) was derived based on the mass balance for OMPs 217 species (Kim et al., 2012; Kim et al., 2017c) using Eq. (3),

$$
J_{O M P S}=\frac{C_{O M P S}\left(V_{D i}+J_{w} A_{m} t\right)}{A_{m} t}=\frac{C_{O M P s} V_{D f}}{A_{m} t}
$$

219 where $C_{O M P s}$ refers to the concentration of OMPs in the DS $\left(\mu \mathrm{g} \mathrm{L}^{-1}\right), V_{d i}$ and $V_{d f}$ are the initial and 220 final DS volumes (L), respectively, and $J_{O M P S}$ refers to the forward flux of the OMPs from the FS 221 toward the DS $\left(\mu \mathrm{g} \mathrm{m}^{-2} \mathrm{~h}^{-1}\right)$.

\subsection{Models for OMPs transport behaviors}

\section{2.5.1. Pore-hindrance transport model}

225 It can be assumed that the FO membrane consisted of several cylindrical capillary tubes with the 226 same radius, where the spherical solute particles can penetrate through these FO membrane pores 227 (Xie et al., 2014b). The pore-hindrance transport model was originally developed to simulate blood 228 flow through individual capillaries (Bungay and Brenner, 1973), but it has also been utilized to 
229 estimate rejections by size exclusion in porous membranes for microfiltration and ultrafiltration 230 (Rodgers and Miller, 1993), and the NF [27], RO [43], and FO processes(Nghiem et al., 2004; Xie 231 et al., 2014b; Yoon and Lueptow, 2005). So, the real OMPs rejection was determined using Eq. 232 (4) (Nghiem et al., 2004; Xie et al., 2014b),

$$
R_{r}=1-\frac{C_{p}}{C_{m}}=1-\frac{\varphi K_{c}}{1-\exp \left(-P_{e}\left(1-\varphi K_{c}\right)\right)},
$$

234 where $R_{r}$ refers to the real rejection of the FO membrane, $C_{p}$ is the permeate OMPs concentration $235\left(\mu \mathrm{g} \mathrm{L}^{-1}\right), C_{m}$ is the OMPs concentration at the membrane surface $\left(\mu \mathrm{g} \mathrm{L}^{-1}\right), K_{c}$ is the hydrodynamic 236 hindrance coefficient for convection, $\varphi$ is the distribution coefficient, and $P_{e}$ is the membrane 237 peclet number. The distribution coefficient (Eq. (5)) is related to the ratio of the OMPs radius to 238 the membrane pore radius (Eq. (6)):

$$
\begin{gathered}
\varphi=(1-\lambda)^{2},(5) \\
\lambda=\frac{r_{s}}{r_{p}}
\end{gathered}
$$

241 The peclet number is defined as the ratio of the convective transport rate to the diffusive transport 242 rate, and can be obtained from Eq. (7),

$$
\mathrm{Pe}=\frac{K_{c} J_{w} l}{K_{d} D \varepsilon},
$$

244 where $K_{d}$ refers to the hydrodynamic hindrance coefficient for diffusion, $D$ refers to the Stokes-

245 Einstein diffusion coefficient $\left(\mathrm{m}^{2} \mathrm{~s}^{-1}\right), l$ is the active layer thickness $(\mathrm{m})$, and $\varepsilon$ refers to the active 246 layer effective porosity. The hydrodynamic hindrance coefficients for convection and diffusion 247 can be determined via Eq. (8) and (9), respectively, which were proposed by Bungay and Brenner 248 (Bungay and Brenner, 1973):

$$
\begin{gathered}
K_{c}=\frac{(2-\varphi) K_{s}}{2 K_{t}}, \\
K_{d}=\frac{6 \pi}{K_{t}} .
\end{gathered}
$$

251 Diffusion may be more dominant than convection in determining the solute transports when $\lambda$ is

252 close to 1. Details on the calculations of the hydrodynamic hindrance coefficients can be found 253 elsewhere (Bungay and Brenner, 1973; Nghiem et al., 2004; Wang et al., 2014). 


\subsubsection{Relationship between real rejection and observed rejection}

256 Since the real rejection is relative to the permeate and the active layer concentrations, as suggested 257 by Eq. (4), the observed rejection $\left(R_{o}=1-c_{p} / c_{f}\right)$ must be calculated to obtain the OMPs 258 forward flux. The observed rejection can be obtained from the relationship between the real 259 rejection and the observed rejection, which is readily derived from concentration polarization in 260 film theory (Nghiem et al., 2004) and given by Eq. (10):

$$
\ln \frac{\left(1-R_{r}\right)}{R_{r}}=\ln \frac{\left(1-R_{o}\right)}{R_{o}}-\frac{J_{w}}{k},
$$

262 where $R_{o}$ refers to the observed rejection of the FO membrane and $k$ refers to the mass transfer 263 coefficient related to the concentration polarization effects near the membrane active layer $\left(\mathrm{m} \mathrm{s}^{-1}\right)$. 264 Details on calculations of mass transfer coefficients are given elsewhere (Kim et al., 2017c).

\subsubsection{Simulation of OMPs forward flux}

267 To simulate the OMPs forward flux, the OMPs concentrations in the FS and the permeate should 268 be determined first. The change in the volume and OMPs concentration of the FS is calculated 269 using a mass balance based on Eq. (11):

$$
\frac{d C_{f}(t)}{d t}=-\frac{J_{w}(t) A_{m} C_{p}(t)}{V_{f}(t)}-\frac{C_{f}(t)}{V_{f}(t)} \frac{V_{f}(t)}{d t},
$$

271 where $C_{f}(t)$ refers to the OMPs concentration in the FS $\left(\mu \mathrm{g} \mathrm{L}^{-1}\right), J_{w}(t)$ refers to the water flux ( $\mathrm{L} \mathrm{m}^{-}$

$\left.272{ }^{2} \mathrm{~h}^{-1}\right), C_{p}(t)$ is the permeate OMPs concentration $\left(\mu \mathrm{g} \mathrm{L}^{-1}\right)$, and $V_{f t}(t)$ refers to the FS volume (L). 273 The water fluxes were obtained from the experimental data (Eq. (1)) and the permeate 274 concentrations were obtained from Eq. (4). All parameters varied with respect to operation time. 275 The OMPs concentration in the DS should also be determined to obtain the average OMPs forward 276 flux. Similarly, the change in the volume and OMPs concentration of the DS is calculated from 277 the mass balance using Eq. (12):

$$
\frac{d C_{d}(t)}{d t}=\frac{J_{w}(t) A_{m} C_{p}(t)}{V_{d}(t)}-\frac{C_{d}(t)}{V_{d}(t)} \frac{V_{d}(t)}{d t} .
$$

279 Then, average OMPs forward flux can be obtained via

$$
J_{S, O M P S}(t)=\frac{C_{d}(t) V_{d}(t)}{A_{m}},
$$

281 where $C_{d}(t)$ refers to the concentration of OMPs in the DS ( $\left.\mu \mathrm{g} \mathrm{L}^{-1}\right), V_{d}(t)$ is the DS volume (L), 282 and $J_{s, O M P_{s}}(t)$ refers to the average forward OMPs flux $\left(\mu \mathrm{g} \mathrm{m}^{-2} \mathrm{~L}^{-1}\right)$. 


\section{Results and discussion}

\subsection{FDFO membrane performance}

286 In the present study, we investigated the effects of employing three different fertilizer chemicals

287 (MAP, DAP, and $\mathrm{KCl}$ ) as the DS in FDFO on the transport mechanisms of OMPs. Our previous study showed that MAP and DAP have similar water fluxes but different RSF, while $\mathrm{KCl}$ has a higher water flux and RSF than either MAP or DAP (Kim et al., 2017c). Here, we first conducted FO experiments with each of these fertilizers as the DS. The results shown in Fig. 1 confirm that $\mathrm{KCl}$ exhibited the highest water flux, while MAP and DAP showed similar water fluxes regardless of the DS concentration, consistent with other studies (Kim et al., 2017c; Phuntsho et al., 2011). As presented in Table S3, DAP had the highest osmotic pressure. Therefore, since water flux is governed by the effective osmotic pressure gradient across the active layer, DAP might be expected to have the highest water flux. However, DAP with the lowest diffusion coefficient is expected to create higher ICP effect likely resulting in lower water flux than $\mathrm{KCl}$. Besides the membrane structural parameter (support layer porosity and tortuosity), the diffusion coefficient of the solutes has a significant influence on the severity of ICP effects (McCutcheon and Elimelech, 2006). On the other hand, MAP had a lower water flux than $\mathrm{KCl}$ despite their similar osmotic pressures (i.e., 49.85 atm and 43.3 atm for MAP $1 \mathrm{M}$ and $\mathrm{KCl} 1 \mathrm{M}$, respectively). This was due to the high diffusivity and low viscosity of $\mathrm{KCl}$ compared to the other fertilizers tested as the DS. It has been shown in the past that high diffusivity and low viscosity of the DS reduce ICP in the support layer, thereby increasing the effective concentration gradient and improving the water flux (Kim et al., 2015).

We also investigated RSF for the three DS, as shown in Fig. 1. KCl showed the highest RSF,

307 be due to the low ICP discussed above. In addition, $\mathrm{KCl}$ has a lower hydrated diameter than either 308 MAP or DAP, which possibly results in high salt permeability (Achilli et al., 2010). Despite the 309 lower diffusivity of DAP (Table S3), DAP showed higher RSF than MAP. We attribute this to 310 DAP containing more ions, and particularly ammonium ions $\left(\mathrm{NH}_{4}{ }^{+}\right)$, than MAP. Therefore, even 311 though DAP had a lower effective concentration gradient, more ions existed on the active layer, 312 which induced the high RSF. Furthermore, due to the reverse diffusion of these ammonium ions, 
313 the $\mathrm{pH}$ of the FS increased during the FDFO operation, consistent with our previous study (Kim 314 et al., 2017c). RSF for the $2 \mathrm{M}$ concentration was proportionately higher than for the $1 \mathrm{M}$ 315 concentration.

316

317

318

319

320

321

322

323

324

325

326

327

328

329

330

331

332

333

334

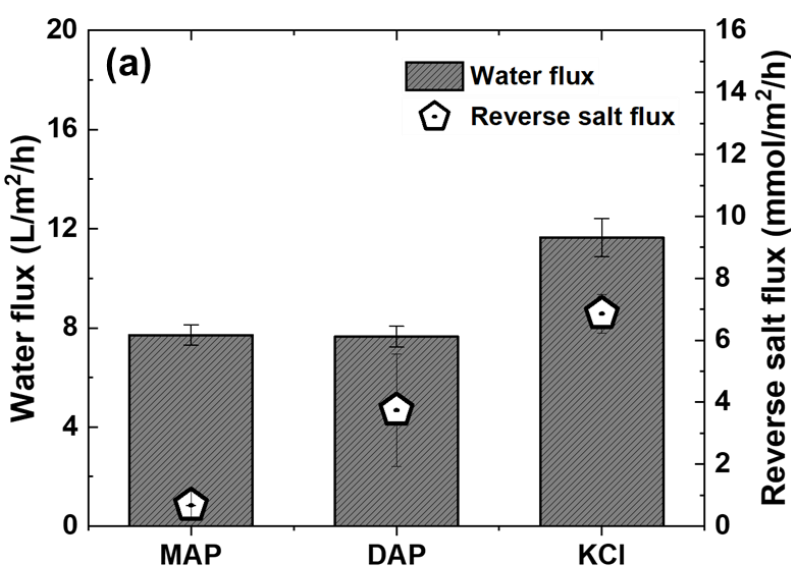

Fertilizers

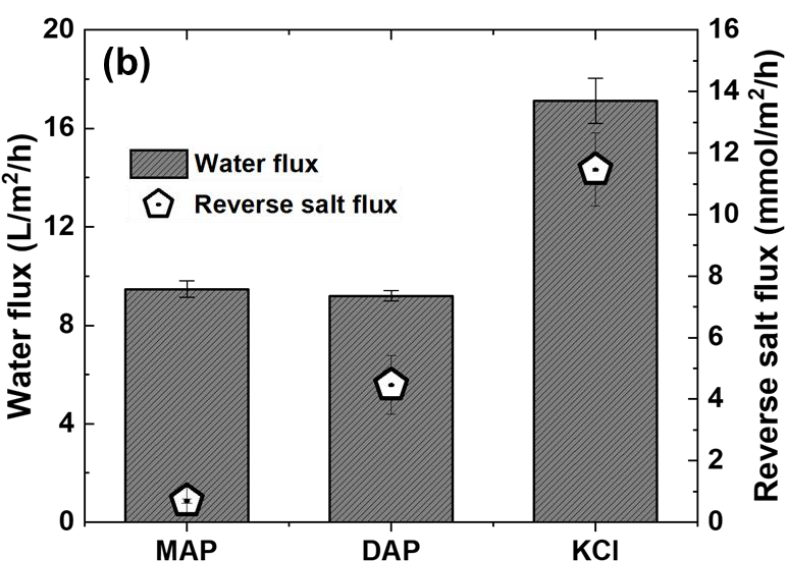

Fertilizers

Figure 1. Water flux (columns, left axis) and reverse salt flux (open symbols, right axis) with three fertilizers (MAP, DAP, and $\mathrm{KCl}$ ) as the DS in FDFO at (a) 1 M DS concentration and (b) 2 M DS concentration.

\subsection{OMPs transport behaviors in FDFO}

In order to investigate the effects of the physicochemical properties of the OMPs surfaces on their transport behaviors during the FDFO process, we chose to use MAP as the DS. Since MAP had a lower specific RSF $\left(0.1 \mathrm{mmol} \mathrm{L}^{-1}\right)$ compared to the other fertilizers (i.e., $0.3 \mathrm{mmol} \mathrm{L}^{-1}$ for DAP and $0.6 \mathrm{mmol} \mathrm{L}^{-1}$ for $\mathrm{KCl}$ ) at $1 \mathrm{M} \mathrm{DS}$ concentrations, we expected it to have a smaller impact on the OMPs transport behavior. To evaluate the OMPs transport behaviors, we measured the OMPs forward flux (see Fig. 2). Primidone showed the lowest OMPs flux (Fig. 2a), followed by caffeine, atenolol, and atrazine. It is well known that OMPs transports in membrane-based processes are dominantly influenced by their molecular weights (Kimura et al., 2004; Kiso et al., 2001; Xie et al., 2014b). However, it was difficult to ascertain a good correlation between the forward OMPs flux and the molecular weight, as shown in Fig. S1a. Even though atrazine and atenolol have higher (or similar) molecular weights than caffeine and primidone, the OMPs fluxes of atrazine and atenolol were higher than those of caffeine and primidone. Atrazine in particular exhibited a 
much higher OMPs flux than primidone despite having a similar molecular weight (i.e., $216 \mathrm{~g} \mathrm{~mol}^{-}$ ${ }^{1}$ and $218 \mathrm{~g} \mathrm{~mol}^{-1}$ for atrazine and primidone, respectively).

When the DS concentration was increased from $1 \mathrm{M}$ to $2 \mathrm{M}$, as shown in Fig. 2b, the OMPs flux slightly decreased (i.e., reduction of $14.2 \%, 9.2 \%$, and $7.1 \%$ for caffeine, atrazine, and primidone, respectively), while the trends among the OMPs did not change significantly. However, atenolol exhibited a different behavior, as its flux increased by $23.1 \%$, from $18.2 \mu \mathrm{g} \mathrm{m}^{-2} \mathrm{~h}^{-1}$ to 22.4 $\mu \mathrm{g} \mathrm{m}^{-2} \mathrm{~h}^{-1}$, which is possibly due to its positive charge. When the FO process is operated at higher water fluxes using higher DS concentrations, it also proportionally increases the atenolol concentration at the membrane surface due to enhanced ECP effects. This likely enhanced OMP flux of the positively charged atenolol aided by the increased electrostatic attraction with a negatively charged FO membrane surface. Similar to the results at 1 M DS concentration, there was no clear correlation between the molecular weight and the OMPs flux (Fig. S1b). These phenomena are likely due to the different physicochemical characteristics (i.e., hydrophobicity and surface charges) of the OMPs.
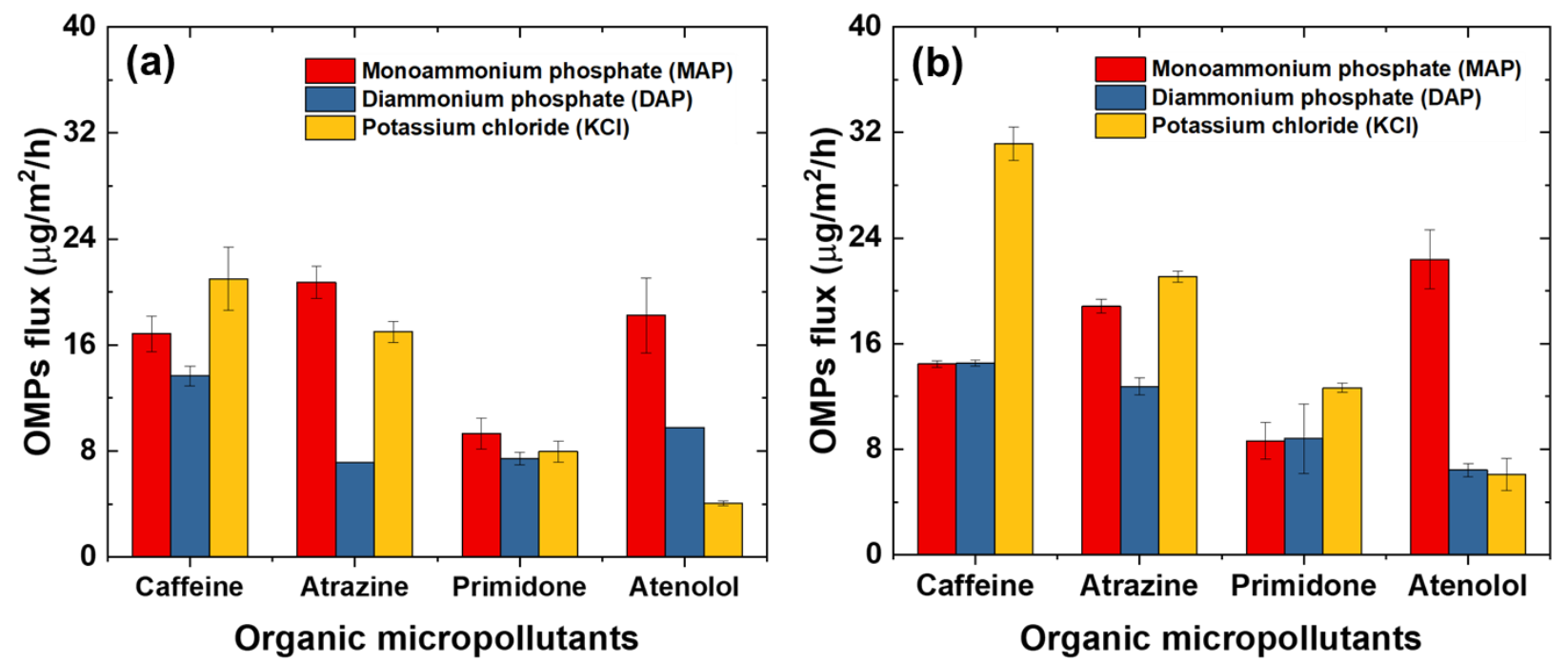

Figure 2. OMPs flux with three fertilizers as the DS (i.e., MAP, DAP, and $\mathrm{KCl}$ ) during FDFO at (a) $1 \mathrm{M}$ DS concentration and (b) $2 \mathrm{M}$ DS concentration.

To further investigate the effects of the DS properties on the OMPs transport behaviors, we also tested DAP and KCl. As discussed in Section 3.1, DAP exhibited a similar water flux but higher RSF than MAP, and $\mathrm{KCl}$ showed both a higher water flux and a higher RSF. When using 
1 M DAP DS, atrazine exhibited the lowest OMPs flux (Fig. 2a) and the highest rejection rate

358 (Table S4, Supplementary Data), followed by primidone, atenolol, and caffeine. Compared with 1 M MAP DS, the OMPs fluxes were reduced overall (i.e., reduction ratio: 18.8\%, 65.7\%, 20.1\%, and $46.4 \%$ for caffeine, atrazine, primidone, and atenolol, respectively). This might be due to the combined effects of the enhanced RSF and the increased FS pH on the OMPs transport behaviors, as suggested in Section 3.1.

When increasing the DS concentration from $1 \mathrm{M}$ to $2 \mathrm{M}$, the OMPs fluxes increased by $6.1 \%$, $79.3 \%$, and $18.3 \%$ for caffeine, atrazine, and primidone, respectively, while for atenolol, it decreased by $34.3 \%$. This might be due to the enhanced water flux of $9.2 \mathrm{~L} \mathrm{~m}^{-2} \mathrm{~h}^{-1}$ at $2 \mathrm{M} \mathrm{DAP}$ from $7.6 \mathrm{~L} \mathrm{~m}^{-2} \mathrm{~h}^{-1}$ at $1 \mathrm{M}$ DAP. Increasing the permeation drag force, i.e., water flux, could deteriate the external concentration polarization, thereby increasing the OMPs forward flux. An increase of the atenolol forward flux can be due to slightly higher increase in the feed $\mathrm{pH}$ when 2 M DAP is used as DS ( $\mathrm{pH}$ 9.73) compared to $1 \mathrm{M}$ DAP as DS ( $\mathrm{pH}$ 9.17) due to higher reverse diffusion of $\mathrm{NH}_{4}{ }^{+}$towards the FS at higher DS concentrations. Comparing the DAP DS with the MAP DS, only atrazine and atenolol exhibited noticeable changes in the OMPs forward flux. This result supports the theory that increases in RSF and FS pH have a more significant effect on the transports of hydrophobic and positively charged OMPs.

We conducted FDFO experiments using $1 \mathrm{M} \mathrm{KCl}$ as the DS to investigate the effect of RSF on the OMPs transport behaviors. Results show that atenolol exhibited the lowest OMPs flux (4.1 $\mu \mathrm{g}^{-1} \mathrm{~m}^{-2} \mathrm{~h}^{-1}$ ), followed by primidone, atrazine, and caffeine. The OMPs fluxes of atrazine, primidone, and atenolol were reduced by $18 \%, 14.4 \%$, and $77.8 \%$, respectively, with $1 \mathrm{M} \mathrm{KCl} \mathrm{DS}$ compared to 1 M MAP DS, despite the enhanced permeation drag force (50.9\%). In contrast, the OMPs flux of caffeine was higher by $24.6 \%$ with $1 \mathrm{M} \mathrm{KCl} \mathrm{DS} \mathrm{than} \mathrm{with} 1 \mathrm{M}$ MAP DS. This may 380 be because the OMPs flux can be dominantly influenced by operational factors, such as water flux, 381 RSF, and physicochemical properties such as molecular size of the OMPs themselves. When the 382 concentration of the $\mathrm{KCl}$ DS was increased to $2 \mathrm{M}$, atenolol had the lowest OMPs flux, followed 383 by primidone, atrazine, and caffeine, similar to the trend seen with $1 \mathrm{M} \mathrm{KCl} \mathrm{DS} \mathrm{(Fig.} \mathrm{2b).}$ 384 Therefore, it is interesting to note that the DS with the highest RSF showed a better linear correlation between the OMPs flux and the molecular weight (Fig. S1, Supplementary Data). 


\subsubsection{Effect of OMPs physicochemical properties on OMPs transport behaviors}

389 For a more detailed investigation of the OMPs transport behaviors during the FDFO process, we 390 simulated the OMPs forward fluxes via the pore-hindrance model and the mass balance, and 391 compared the simulation results with the experimental data. To elucidate the effect of 392 physicochemical properties on the OMPs transports, we modeled the OMPs forward flux with 1 393 M MAP DS (Fig. 3a). Interestingly, the forward fluxes of all the OMPs were increased in the 394 simulations compared to the experiments because the pore-hindrance model considers only the 395 steric hindrance between the OMPs and the FO membrane; their chemical properties were not 396 taken into account. The results presented in the table in Fig. 3a show that atrazine and atenolol 397 exhibited more significant differences between their modeled and experimental OMPs fluxes than 398 caffeine and primidone, possibly because of their different physicochemical properties (i.e., 399 hydrophobicity and surface charges) (Fig. 4a). The surfaces of caffeine, atrazine, and primidone 400 have similar neutral charges but different hydrophobicities (Table 1). Atrazine has a hydrophobic 401 property and this could possibly cause adsorption of atrazine onto the membrane surface, thus, 402 enhancing OMPs transport through the moderately hydrophilic FO membrane (the contact angle 403 of the FO membrane's active layer was $79.5^{\circ}$, as shown in Table 2). To further confirm this 404 hypothesis, we calculated the adsorbed amounts of OMPs based on their mass balance; the results 405 are presented in Table 3. Atrazine, which has a neutrally charged surface, exhibited the second 406 highest adsorbed amount (i.e., $2.79 \mathrm{mg} \mathrm{m}^{-2}, 0.17 \mathrm{mg} \mathrm{m}^{-2}, 1.27 \mathrm{mg} \mathrm{m}^{-2}$, and $3.31 \mathrm{mg} \mathrm{m}^{-2}$ for atrazine, 407 caffeine, primidone, and atenolol, respectively), which resulted in a higher concentration of OMPs 408 in the AL. Therefore, it held true that the hydrophobic interaction could be the dominant 409 mechanism for the transport behavior of atrazine. When the surface hydrophobicity was similar 410 (i.e., caffeine and primidone), caffeine showed a higher OMPs flux than primidone, implying that 411 the molecular weight was the dominant factor determining the forward flux of the OMPs.

413 Table 3. Adsorbed amounts of OMPs on the membrane surface. Adsorbed amounts of OMPs were 414 estimated via simple mass balance.

\begin{tabular}{l|l|l|l|l|}
\hline & Caffeine & Atrazine & Primidone & Atenolol \\
\hline \hline $\begin{array}{l}\text { Adsorbed amount } \\
\left(\mathrm{mg} \mathrm{m}^{-2}\right)\end{array}$ & 0.17 & 2.79 & 1.27 & 3.31 \\
\hline
\end{tabular}


416 In addition to hydrophobicity, the surface charges of OMPs can seriously influence their

417 transport behavior via electrostatic repulsion or electrostatic attraction with electrically charged

418 membranes (Xie et al., 2012b). Fig. 2a shows a higher forward flux for atenolol despite its high

419 molecular weight and this might be due to the electrostatic attraction caused by the positively

420 charged atenolol OMP and the negatively charged surface of the FO membrane, as shown in Table

4211 and Table 2. In Table 3, we see that atenolol had the highest amount of OMPs $\left(3.31 \mathrm{mg} \mathrm{m}^{-2}\right)$

422 adsorbed on the membrane surface. This could have induced a high OMPs concentration gradient

423 across the active layer, thereby enhancing the forward flux of atrazine. When the MAP DS

424 concentration was increased from $1 \mathrm{M}$ to $2 \mathrm{M}$, the forward flux of atenolol was enhanced, which

425 can be explained due to enhanced ECP when FO is operated at higher water fluxes. This enhanced

426 atenolol concentration at the membrane surface increases its forward flux further aided by the

427 electrostatic attraction between the positively charged atenolol and negatively charged membrane

428 surface. Although the concentrations of the other OMPs also increases at the membrane surface

429 when the FO is operated at higher flux (higher ECP), however, their forward flux decreased which

430 is a rather unexpected behavior since forward solute fluxes are generally a function of its

431 concentration at the membrane surface. Hence, further studies are required to gain better

432 understanding of why the forward fluxes of other OMPs behave differently when MAP DS is

433 operated at higher concentrations.

434
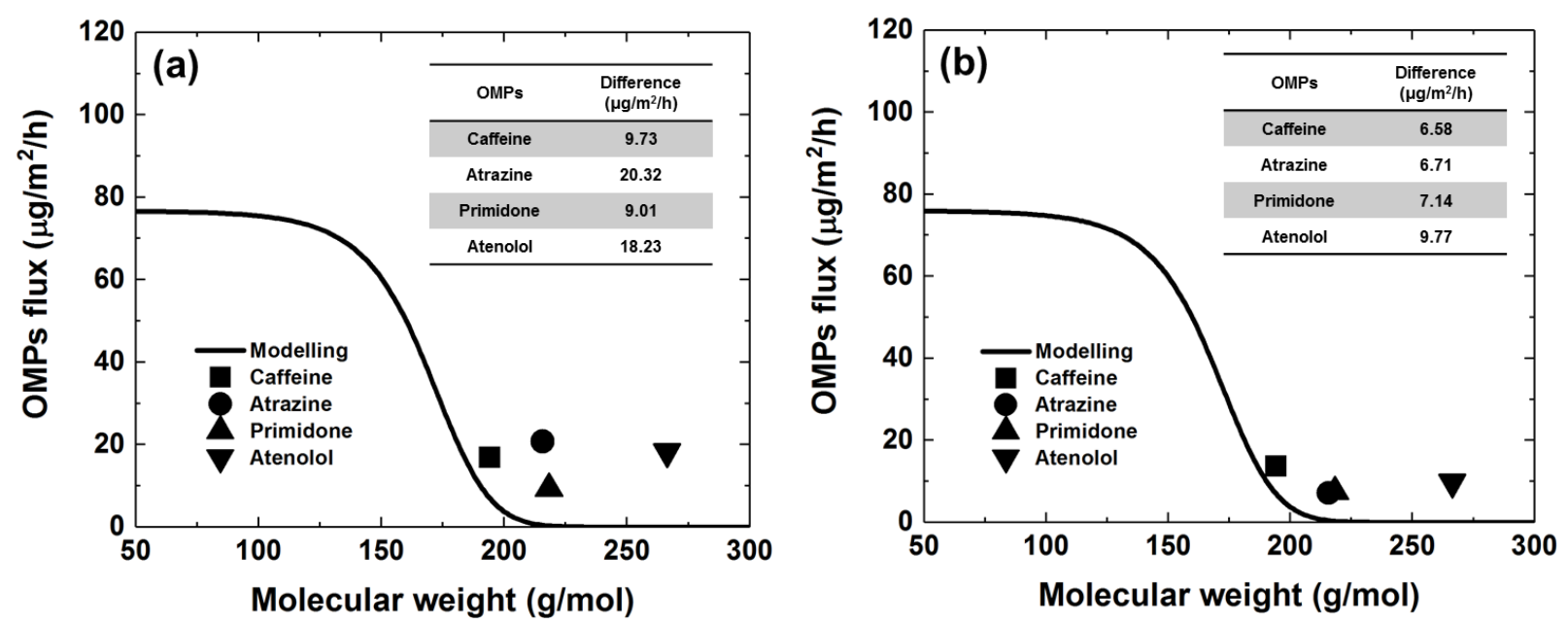

435 


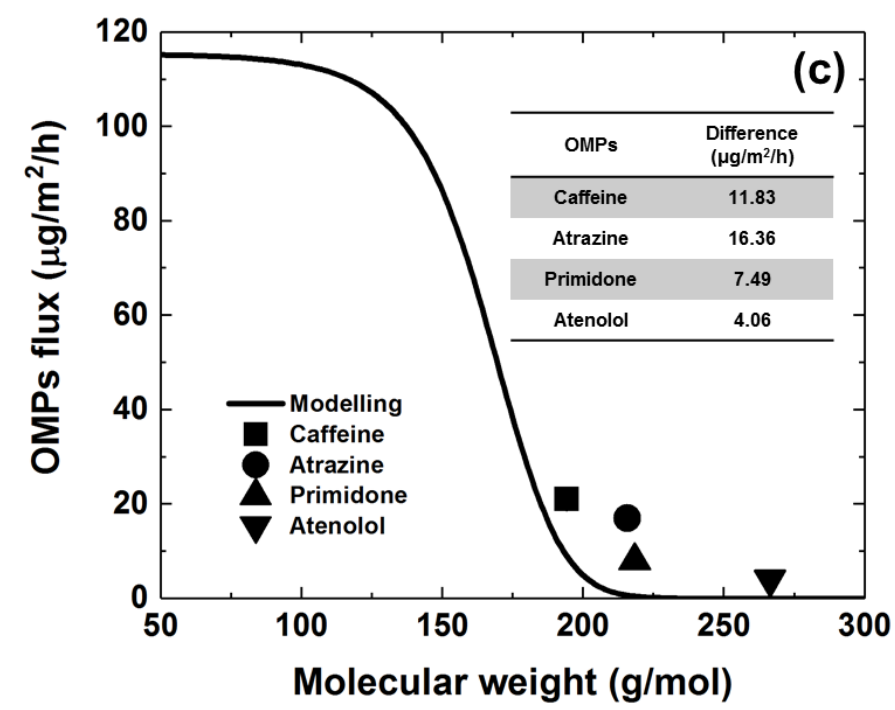

Figure 3. Model predictions (solid line) for OMPs flux with the varying solute molecular weight 438 simulated by the pore-hindrance transport model for (a) MAP DS, (b) DAP DS, and (c) KCl DS 439 at 1 M DS concentration. Also included are the measured solute forward fluxes of the OMPs: 440 caffeine, atrazine, primidone, and atenolol. Tables in each panel indicate the difference between 441 the modeled OMPs flux and the experimental data. The relevant parameters from Table 1 and 442 Table S2 were employed for the model calculation; other parameters were adopted from the 443 experimental data presented in Fig. 1a.

\subsubsection{Effect of alkaline fertilizer (DAP) DS on OMPs transport behaviors}

446 We also investigated the effect of an alkaline fertilizer DS (in this case, we used DAP) on the 447 transport behavior of OMPs during FDFO. An OMPs flux with 1 M DAP DS was simulated using 448 the experimental average water flux, presented in Fig. 3b. The differences between the modeled 449 OMPs flux and the experimental data were reduced for all the OMPs, but the forward fluxes of 450 atrazine and atenolol decreased compared to 1 M MAP DS. This could be due to the enhanced 451 RSF combined with a similar water flux (Xie et al., 2012a). The DAP DS had a higher RSF (i.e., $452 \quad 2.5 \mathrm{mmol} \mathrm{m}^{-2} \mathrm{~h}^{-1}$ and $0.7 \mathrm{mmol} \mathrm{m}^{-2} \mathrm{~h}^{-1}$, respectively) than the MAP DS, while the water flux was 453 very similar (i.e., $7.6 \mathrm{~L} \mathrm{~m}^{-2} \mathrm{~h}^{-1}$ and $7.7 \mathrm{~L} \mathrm{~m}^{-2} \mathrm{~h}^{-1}$, respectively) as shown in Fig. 1a. A high RSF 454 might hinder the transport of feed solutes through the FO membrane, resulting in a lower OMPs 455 forward flux. In addition, the FS pH of the DAP DS increased from 7.05 to 9.17 during $10 \mathrm{~h}$ of 456 operation; this could potentially change the membrane surface properties (e.g., by decreasing the 
contact angle and slightly increasing the zeta potential) of the FO membrane due to hydrophilic 458 surface functional groups (Xie et al., 2012b) as well as the surface charge of atenolol because of 459 its pKa value of 9.6. Particularly, a reduced contact angle would suggest hydration swelling of the 460 active layer (Ahmad et al., 2008). In this case, atrazine would not reach the FO membrane due to 461 steric hindrance by the water molecules on the membrane surface, making hydrophobic interaction negligible (Fig. 4b). As a result, OMPs (i.e., atrazine and primidone) with similar molecular weights but different surface properties exhibited a similar OMPs flux.

For atenolol, we hypothesized that the increase in FS pH from 7.05 to 9.17, resulting in a pKa value of 9.6, changed the surface charge from positive to neutral while other OMPs maintained their surface charge properties. Therefore, atenolol was less adsorbed on the active layer and less likely to be transported into the DS (Fig. 4b). To verify this hypothesis, we calculated the adsorbed amounts of atenolol via the mass balance as $3.31 \mathrm{mg} \mathrm{m}^{-2}$ and $2.27 \mathrm{mg} \mathrm{m}^{-2}$ for MAP $1 \mathrm{M}$ and DAP $1 \mathrm{M}$, respectively. These amounts were similar to those of another study that found atenolol adsorption (the retardation factor) on a sandy aquifer material was reduced from 23.3 to 15.8 when pH was increased from 4 to 8 (Schaffer et al., 2012).

By simulating the OMPs flux with 2 M DAP DS using the experimental average water flux (Fig. S2b), we found that the OMPs transport behavior was dominantly influenced by enhanced steric hindrance. Besides, FS pH became 9.73 which is higher than that of 1 M DAP DS (pH 9.17), which further reduced the forward flux of atenolol by $34.3 \%$. At higher $\mathrm{pH}$, the atenolol loses its positive charge to become neutral thereby reducing the electrostatic attraction between the atenolol and charged membrane surface and hence lowering its forward flux. This is evident from the consistent trends shown in Fig. S2b and Fig. 3b, which implicate the increased RSF and a change in the surface properties of both the FO membrane and the OMPs resulting from the increased $\mathrm{pH}$ of the FS.

\subsubsection{Effect of DS with high $R S F(\mathrm{KCl})$ on OMPs transport behaviors}

483 Lastly, we simulated the OMPs flux with $1 \mathrm{M} \mathrm{KCl} \mathrm{DS} \mathrm{using} \mathrm{experimental} \mathrm{data} \mathrm{and} \mathrm{found} \mathrm{a} \mathrm{high}$ water flux and high RSF. The modeled OMPs flux was noticeably increased with the $\mathrm{KCl}$ DS compared to the MAP DS and DAP DS. This was due to the high water flux of the $\mathrm{KCl}$ DS compared to the MAP and DAP DS. When comparing the modeled OMPs flux with the 
experimental OMPs flux, atenolol exhibited the smallest difference, followed by primidone, 488 caffeine, and atrazine (Fig. 3c), indicating that the OMPs with high molecular weights were more easily influenced by a high RSF. Therefore, we hypothesized that the forward fluxes of the OMPs were dominantly determined by the interplay among the water flux, RSF, and molecular size of the OMPs. A high water flux causes enhanced ECP, potentially leading to an increased OMPs flux (Kim et al., 2017b). Hence, caffeine, which has a low molecular weight, may be more easily transferred to the DS than OMPs of higher weight. In addition, the transport of the OMPs was significantly influenced by their molecular weights due to the hindrance effect of a high RSF, as shown in Fig. 4c. Consequently, the forward flux of OMPs with high molecular weights became lower in $1 \mathrm{M} \mathrm{KCl}$ DS than in $1 \mathrm{M}$ MAP DS. Fig. S1e indicates that the forward OMPs flux was a function of molecular weight when using $1 \mathrm{M} \mathrm{KCl} \mathrm{DS}$.

To validate this hypothesis, we compared the OMPs forward fluxes of $2 \mathrm{M} \mathrm{KCl} \mathrm{DS} \mathrm{(Fig.} \mathrm{S1f)}$ and 2 M MAP DS (Fig. S1b). The results show that the forward fluxes of all the OMPs except atenolol were increased, supporting the hypothesis that the transport of OMPs with a high molecular weight is more affected by RSF than a high water flux. The removal rates of all the OMPs were increased with the KCl DS compared to the MAP DS (Table S4). This result agrees well with the results from other studies that a high water flux leads to a decrease in removal rates due to the dilution effect (Lee et al., 2004; Xie et al., 2013). Interestingly, the trends of the three OMPs with neutral surfaces (caffeine, atrazine, and primidone) with the $\mathrm{KCl}$ DS were similar to the trends with the MAP DS, but not the DAP DS. The reverse diffusion of the KCl DS did not influence the FS pH and, therefore, the surface chemical properties of the FO membrane were a governing factor in the transport of OMPs with a relatively low molecular weight.

The findings from the present study have significant implications for optimizing the FDFO process for treating wastewater that contains OMPs. When using MAP or $\mathrm{KCl}$ as the DS, the rejection of the OMPs was governed by the physicochemical properties of their surfaces. However,

513 caused by the backward diffusion of $\mathrm{NH}_{4}{ }^{+}$in the DS. This implies that an alkaline DS is 514 recommended for the effective removal of OMPs from wastewater. We found that the 515 experimental OMPs fluxes were higher than the theoretical OMPs fluxes obtained from the pore516 hindrance model. This discrepancy is due to the solution-diffusion model being dominant for non- 
517 porous membranes such as NF, RO, and FO membranes. Nevertheless, because the pore-hindrance 518 model considers only the steric hindrance effect by size exclusion, it still helps us to understand 519 how the surface properties of the OMPs and the FO membrane influenced the OMPs transport 520 behaviors.

\section{Conclusion}

523 We systematically investigated the OMPs transport mechanisms in FDFO using four different 524 OMPs with different molecular weights and surface physicochemical characteristics and three 525 different fertilizers as the DS. The transport behaviors of the OMPs were simulated using the pore526 hindrance transport model in order to identify the effect of the physicochemical properties of the 527 OMPs surfaces on their transport. The main findings drawn from the present study can be 528 summarized briefly as follows:

529 - $\mathrm{KCl}$ showed the highest water flux and RSF; MAP and DAP exhibited similar water fluxes but 530 different RSF.

531 - When using either the MAP or KCl DS (which had a moderate water flux and low RSF), the 532 physicochemical properties (i.e., hydrophobicity and surface charge) of the OMPs determined 533 their transport behavior. However, the remarkably increased RSF caused by using $\mathrm{KCl}$ as the 534 DS could hamper the transport of OMPs with high molecular weights.

535 - With the DAP DS, the FO membrane was more hydrated because of the increased pH. RSF 536 was also enhanced, which may have helped prevent the transport of OMPs through the FO 537 membrane. Thus, rejection of all the tested OMPs was enhanced.

538 - The pore-hindrance model was instrumental in understanding the effects of the hydrodynamic properties and the physicochemical properties on OMPs transports. 
(a) MAP DS under AL-FS mode (b) DAP DS under AL-FS mode

(c) KCI DS under AL-FS mode

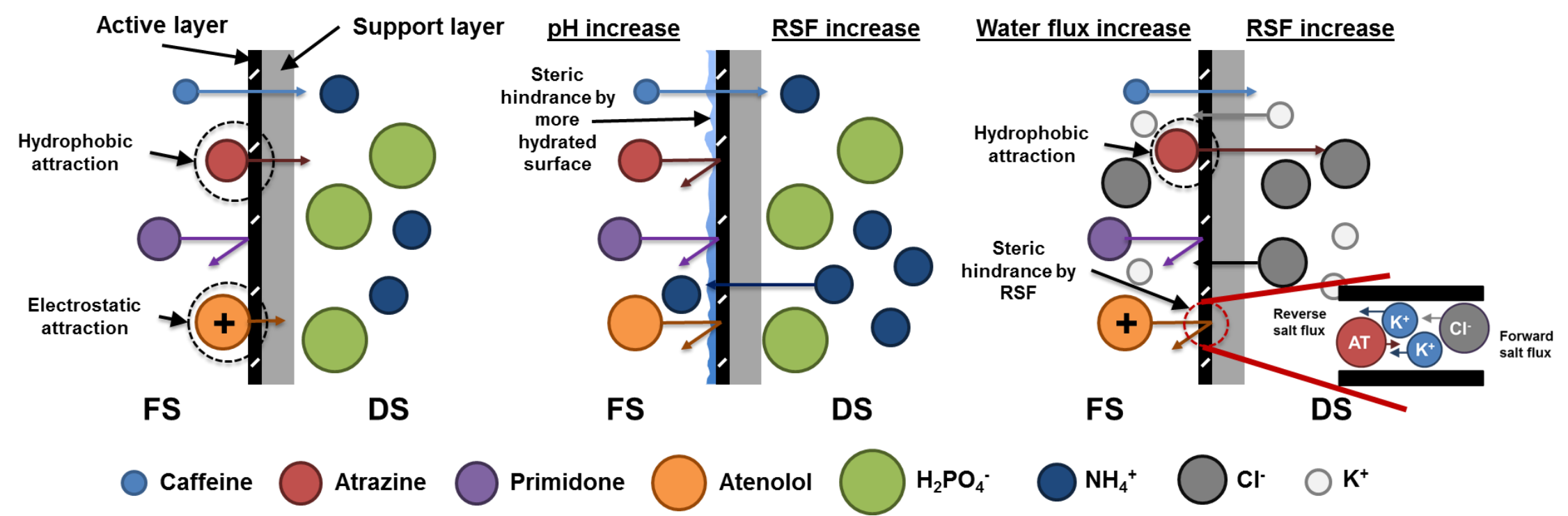

Figure 4. Schematic descriptions of OMPs transport mechanisms in FO. RSF plays an important role in determining the OMPs transports. With MAP DS, which has low RSF, the OMPs transports are dominantly influenced by their properties (i.e., molecular weights, surface charges, and surface hydrophobicity). With DAP DS, which has an intermediate RSF, an increase in FS pH alters the surface physicochemical properties of both the FO membrane and the OMPs; hence, the OMPs transport was significantly influenced. With $\mathrm{KCl}$ DS, which has a high RSF, the transport behavior of the OMPs was affected by both the high RSF and the surface properties of OMPs. 


\section{Acknowledgements}

The research reported in this publication was supported by funding from King Abdullah University of Science and Technology (KAUST). The support of the staff at the KAUST Water Desalination $\&$ Reuse Center (WDRC) is also greatly appreciated.

\section{References}

(NSW), D.o.E.a.C., 2004. Environmental Guidelines: Use of Effluent by Irrigation. Department of Environment and Conservation (NSW).

Achilli, A., Cath, T.Y., Childress, A.E., 2010. Selection of inorganic-based draw solutions for forward osmosis applications. Journal of Membrane Science 364, 233-241.

Ahmad, A.L., Tan, L.S., Abd. Shukor, S.R., 2008. The role of pH in nanofiltration of atrazine and dimethoate from aqueous solution. Journal of Hazardous Materials 154, 633-638.

Alturki, A.A., McDonald, J.A., Khan, S.J., Price, W.E., Nghiem, L.D., Elimelech, M., 2013. Removal of trace organic contaminants by the forward osmosis process. Separation and Purification Technology 103, 258-266.

Arslan, M., Ullah, I., Müller, J.A., Shahid, N., Afzal, M., 2017. Organic Micropollutants in the Environment: Ecotoxicity Potential and Methods for Remediation, in: Anjum, N.A., Gill, S.S., Tuteja, N. (Eds.), Enhancing Cleanup of Environmental Pollutants: Volume 1: Biological Approaches. Springer International Publishing, Cham, pp. 65-99.

Barbosa, M.O., Moreira, N.F.F., Ribeiro, A.R., Pereira, M.F.R., Silva, A.M.T., 2016. Occurrence and removal of organic micropollutants: An overview of the watch list of EU Decision 2015/495. Water Research 94, 257-279.

Bernhard, M., Müller, J., Knepper, T.P., 2006. Biodegradation of persistent polar pollutants in wastewater: Comparison of an optimised lab-scale membrane bioreactor and activated sludge treatment. Water Research 40, 3419-3428.

Bungay, P.M., Brenner, H., 1973. The motion of a closely-fitting sphere in a fluid-filled tube. International Journal of Multiphase Flow 1, 25-56. 
Carballa, M., Omil, F., Lema, J.M., Llompart, M.a., García-Jares, C., Rodríguez, I., Gómez, M., Ternes, T., 2004. Behavior of pharmaceuticals, cosmetics and hormones in a sewage treatment plant. Water Research 38, 2918-2926.

Chekli, L., Kim, J.E., El Saliby, I., Kim, Y., Phuntsho, S., Li, S., Ghaffour, N., Leiknes, T., Kyong Shon, H., 2017a. Fertilizer drawn forward osmosis process for sustainable water reuse to grow hydroponic lettuce using commercial nutrient solution. Separation and Purification Technology 181, 18-28.

Chekli, L., Kim, Y., Phuntsho, S., Li, S., Ghaffour, N., Leiknes, T., Shon, H.K., 2017 b.

Evaluation of fertilizer-drawn forward osmosis for sustainable agriculture and water reuse in arid regions. Journal of Environmental Management 187, 137-145.

Chekli, L., Phuntsho, S., Kim, J.E., Kim, J., Choi, J.Y., Choi, J.-S., Kim, S., Kim, J.H., Hong, S., Sohn, J., Shon, H.K., 2016. A comprehensive review of hybrid forward osmosis systems: Performance, applications and future prospects. Journal of Membrane Science 497, 430-449.

Chong, T.H., Loo, S.-L., Krantz, W.B., 2015. Energy-efficient reverse osmosis desalination process. Journal of Membrane Science 473, 177-188.

Clara, M., Strenn, B., Gans, O., Martinez, E., Kreuzinger, N., Kroiss, H., 2005. Removal of selected pharmaceuticals, fragrances and endocrine disrupting compounds in a membrane bioreactor and conventional wastewater treatment plants. Water Research 39, 4797-4807. Escher, B.I., Allinson, M., Altenburger, R., Bain, P.A., Balaguer, P., Busch, W., Crago, J., Denslow, N.D., Dopp, E., Hilscherova, K., Humpage, A.R., Kumar, A., Grimaldi, M., Jayasinghe, B.S., Jarosova, B., Jia, A., Makarov, S., Maruya, K.A., Medvedev, A., Mehinto, A.C., Mendez, J.E., Poulsen, A., Prochazka, E., Richard, J., Schifferli, A., Schlenk, D., Scholz, S., Shiraishi, F., Snyder, S., Su, G., Tang, J.Y.M., Burg, B.v.d., Linden, S.C.v.d., Werner, I., Westerheide, S.D., Wong, C.K.C., Yang, M., Yeung, B.H.Y., Zhang, X., Leusch, F.D.L., 2014. Benchmarking Organic Micropollutants in Wastewater, Recycled Water and Drinking Water with In Vitro Bioassays. Environmental Science \& Technology 48, 19401956.

Fujioka, T., Khan, S.J., McDonald, J.A., Nghiem, L.D., 2015. Rejection of trace organic chemicals by a nanofiltration membrane: the role of molecular properties and effects of caustic cleaning. Environmental Science: Water Research \& Technology 1, 846-854. 
Ghaffour, N., Missimer, T.M., Amy, G.L., 2013. Technical review and evaluation of the economics of water desalination: Current and future challenges for better water supply sustainability. Desalination 309, 197-207.

Grandclément, C., Seyssiecq, I., Piram, A., Wong-Wah-Chung, P., Vanot, G., Tiliacos, N., Roche, N., Doumenq, P., 2017. From the conventional biological wastewater treatment to hybrid processes, the evaluation of organic micropollutant removal: A review. Water Research 111, 297-317.

Hai, F.I., Tessmer, K., Nguyen, L.N., Kang, J., Price, W.E., Nghiem, L.D., 2011. Removal of micropollutants by membrane bioreactor under temperature variation. Journal of Membrane Science 383, 144-151.

Jamil, S., Jeong, S., Vigneswaran, S., 2016. Application of pressure assisted forward osmosis for water purification and reuse of reverse osmosis concentrate from a water reclamation plant. Separation and Purification Technology 171, 182-190.

Jeong, H., Seong, C., Jang, T., Park, S., 2016. Classification of Wastewater Reuse for Agriculture: A Case Study in South Korea. Irrigation and Drainage 65, 76-85.

Jin, X., She, Q., Ang, X., Tang, C.Y., 2012. Removal of boron and arsenic by forward osmosis membrane: Influence of membrane orientation and organic fouling. Journal of Membrane Science 389, 182-187.

Kim, C., Lee, S., Shon, H.K., Elimelech, M., Hong, S., 2012. Boron transport in forward osmosis: Measurements, mechanisms, and comparison with reverse osmosis. Journal of Membrane Science 419-420, 42-48.

Kim, J.E., Phuntsho, S., Ali, S.M., Choi, J.Y., Shon, H.K., 2018. Forward osmosis membrane modular configurations for osmotic dilution of seawater by forward osmosis and reverse osmosis hybrid system. Water Research 128, 183-192.

Kim, Y., Chekli, L., Shim, W.-G., Phuntsho, S., Li, S., Ghaffour, N., Leiknes, T., Shon, H.K., 2016. Selection of suitable fertilizer draw solute for a novel fertilizer-drawn forward osmosisanaerobic membrane bioreactor hybrid system. Bioresource Technology 210, 26-34.

Kim, Y., Lee, S., Shon, H.K., Hong, S., 2015. Organic fouling mechanisms in forward osmosis membrane process under elevated feed and draw solution temperatures. Desalination 355, 169-177. 
Kim, Y., Li, S., Chekli, L., Phuntsho, S., Ghaffour, N., Leiknes, T., Shon, H.K., 2017a. Influence of fertilizer draw solution properties on the process performance and microbial community structure in a side-stream anaerobic fertilizer-drawn forward osmosis - ultrafiltration bioreactor. Bioresource Technology 240, 149-156.

Kim, Y., Li, S., Chekli, L., Woo, Y.C., Wei, C.-H., Phuntsho, S., Ghaffour, N., Leiknes, T., Shon, H.K., 2017b. Assessing the removal of organic micro-pollutants from anaerobic membrane bioreactor effluent by fertilizer-drawn forward osmosis. Journal of Membrane Science 533, 84-95.

Kim, Y., Li, S., Chekli, L., Woo, Y.C., Wei, C.-H., Phuntsho, S., Ghaffour, N., Leiknes, T., Shon, H.K., 2017c. Assessing the removal of organic micro-pollutants from anaerobic membrane bioreactor effluent by fertilizer-drawn forward osmosis. Journal of Membrane Science 533, 84-95.

Kim, Y., Woo, Y.C., Phuntsho, S., Nghiem, L.D., Shon, H.K., Hong, S., 2017d. Evaluation of fertilizer-drawn forward osmosis for coal seam gas reverse osmosis brine treatment and sustainable agricultural reuse. Journal of Membrane Science 537, 22-31.

Kimura, K., Toshima, S., Amy, G., Watanabe, Y., 2004. Rejection of neutral endocrine disrupting compounds (EDCs) and pharmaceutical active compounds (PhACs) by RO membranes. Journal of Membrane Science 245, 71-78.

Kiso, Y., Sugiura, Y., Kitao, T., Nishimura, K., 2001. Effects of hydrophobicity and molecular size on rejection of aromatic pesticides with nanofiltration membranes. Journal of Membrane Science 192, 1-10.

Krzeminski, P., Leverette, L., Malamis, S., Katsou, E., 2017. Membrane bioreactors - A review on recent developments in energy reduction, fouling control, novel configurations, LCA and market prospects. Journal of Membrane Science 527, 207-227.

Lee, S., Amy, G., Cho, J., 2004. Applicability of Sherwood correlations for natural organic matter (NOM) transport in nanofiltration (NF) membranes. Journal of Membrane Science 240, 49-65.

Lee, S., Boo, C., Elimelech, M., Hong, S., 2010. Comparison of fouling behavior in forward osmosis (FO) and reverse osmosis (RO). Journal of Membrane Science 365, 34-39. 
Li, S., Kim, Y., Chekli, L., Phuntsho, S., Shon, H.K., Leiknes, T., Ghaffour, N., 2017a. Impact of reverse nutrient diffusion on membrane biofouling in fertilizer-drawn forward osmosis. Journal of Membrane Science 539, 108-115.

Li, S., Kim, Y., Phuntsho, S., Chekli, L., Shon, H.K., Leiknes, T., Ghaffour, N., 2017b. Methane production in an anaerobic osmotic membrane bioreactor using forward osmosis: Effect of reverse salt flux. Bioresource Technology 239, 285-293.

McCutcheon, J.R., Elimelech, M., 2006. Influence of concentrative and dilutive internal concentration polarization on flux behavior in forward osmosis. Journal of Membrane Science 284, 237-247.

Nghiem, L.D., Schäfer, A.I., Elimelech, M., 2004. Removal of Natural Hormones by Nanofiltration Membranes: Measurement, Modeling, and Mechanisms. Environmental Science \& Technology 38, 1888-1896.

Pérez, S., Eichhorn, P., Aga, D.S., 2005. Evaluating the biodegradability of sulfamethazine, sulfamethoxazole, sulfathiazole, and trimethoprim at different stages of sewage treatment. Environmental Toxicology and Chemistry 24, 1361-1367.

Phuntsho, S., Shon, H.K., Hong, S., Lee, S., Vigneswaran, S., 2011. A novel low energy fertilizer driven forward osmosis desalination for direct fertigation: Evaluating the performance of fertilizer draw solutions. Journal of Membrane Science 375, 172-181.

Qu, X., Cai, X., Zhang, M., Lin, H., Leihong, Z., Liao, B.-Q., 2018. A facile method for simulating randomly rough membrane surface associated with interface behaviors. Applied Surface Science 427, 915-921.

Radjenović, J., Petrović, M., Ventura, F., Barceló, D., 2008. Rejection of pharmaceuticals in nanofiltration and reverse osmosis membrane drinking water treatment. Water Research 42 , 3601-3610.

Rodgers, V.G.J., Miller, K.D., 1993. Analysis of steric hindrance reduction in pulsed protein ultrafiltration. Journal of Membrane Science 85, 39-58.

Schaffer, M., Boxberger, N., Börnick, H., Licha, T., Worch, E., 2012. Sorption influenced transport of ionizable pharmaceuticals onto a natural sandy aquifer sediment at different $\mathrm{pH}$. Chemosphere 87, 513-520. 
Shannon, M.A., Bohn, P.W., Elimelech, M., Georgiadis, J.G., Mariñas, B.J., Mayes, A.M., 2008. Science and technology for water purification in the coming decades. Nature 452, 301. Snyder, S.A., Westerhoff, P., Yoon, Y., Sedlak, D.L., 2003. Pharmaceuticals, Personal Care Products, and Endocrine Disruptors in Water: Implications for the Water Industry. Environmental Engineering Science 20, 449-469.

Tang, J.Y.M., McCarty, S., Glenn, E., Neale, P.A., Warne, M.S.J., Escher, B.I., 2013. Mixture effects of organic micropollutants present in water: Towards the development of effect-based water quality trigger values for baseline toxicity. Water Research 47, 3300-3314.

Teng, J., Shen, L., Yu, G., Wang, F., Li, F., Zhou, X., He, Y., Lin, H., 2018. Mechanism analyses of high specific filtration resistance of gel and roles of gel elasticity related with membrane fouling in a membrane bioreactor. Bioresource technology 257, 39-46.

Teng, J., Zhang, M., Leung, K.-T., Chen, J., Hong, H., Lin, H., Liao, B.-Q., 2019. A unified thermodynamic mechanism underlying fouling behaviors of soluble microbial products (SMPs) in a membrane bioreactor. Water Research 149, 477-487.

Valladares Linares, R., Yangali-Quintanilla, V., Li, Z., Amy, G., 2011. Rejection of micropollutants by clean and fouled forward osmosis membrane. Water Research 45, 67376744.

Wang, J., Dlamini, D.S., Mishra, A.K., Pendergast, M.T.M., Wong, M.C.Y., Mamba, B.B., Freger, V., Verliefde, A.R.D., Hoek, E.M.V., 2014. A critical review of transport through osmotic membranes. Journal of Membrane Science 454, 516-537.

Wilke, C.R., Chang, P., 1955. Correlation of diffusion coefficients in dilute solutions. AIChE Journal 1, 264-270.

Xie, M., Lee, J., Nghiem, L.D., Elimelech, M., 2015. Role of pressure in organic fouling in forward osmosis and reverse osmosis. Journal of Membrane Science 493, 748-754.

Xie, M., Nghiem, L.D., Price, W.E., Elimelech, M., 2012a. Comparison of the removal of hydrophobic trace organic contaminants by forward osmosis and reverse osmosis. Water Research 46, 2683-2692.

Xie, M., Nghiem, L.D., Price, W.E., Elimelech, M., 2014a. Impact of organic and colloidal fouling on trace organic contaminant rejection by forward osmosis: Role of initial permeate flux. Desalination 336, 146-152. 
Xie, M., Nghiem, L.D., Price, W.E., Elimelech, M., 2014b. Relating rejection of trace organic contaminants to membrane properties in forward osmosis: Measurements, modelling and implications. Water Research 49, 265-274.

Xie, M., Price, W.E., Nghiem, L.D., 2012b. Rejection of pharmaceutically active compounds by forward osmosis: Role of solution $\mathrm{pH}$ and membrane orientation. Separation and Purification Technology 93, 107-114.

Xie, M., Price, W.E., Nghiem, L.D., Elimelech, M., 2013. Effects of feed and draw solution temperature and transmembrane temperature difference on the rejection of trace organic contaminants by forward osmosis. Journal of Membrane Science 438, 57-64.

Xu, P., Drewes, J.E., Bellona, C., Amy, G., Kim, T.U., Adam, M., Heberer, T., 2005. Rejection of emerging organic micropollutants in nanofiltration-reverse osmosis membrane applications. Water environment research : a research publication of the Water Environment Federation 77, 40-48.

Yoon, Y., Lueptow, R.M., 2005. Removal of organic contaminants by RO and NF membranes. Journal of Membrane Science 261, 76-86.

Zhang, M., Hong, H., Lin, H., Shen, L., Yu, H., Ma, G., Chen, J., Liao, B.-Q., 2018. Mechanistic insights into alginate fouling caused by calcium ions based on terahertz time-domain spectra analyses and DFT calculations. Water Research 129, 337-346. 